\title{
BMJ Open Multimorbidity in cardiovascular disease and association with life satisfaction: a Chinese national cross- sectional study
}

\author{
Guihao Liu (D) , Yunlian Xue (1) , Yuanhui Liu, Sheng Wang, Qingshan Geng
}

To cite: Liu G, Xue Y, Liu Y, et al. Multimorbidity in cardiovascular disease and association with life satisfaction: a Chinese national cross-sectional study. BMJ Open 2020;10:e042950. doi:10.1136/ bmjopen-2020-042950

- Prepublication history for this paper is available online. To view these files, please visit the journal online (http://dx.doi. org/10.1136/bmjopen-2020042950).

GL and YX contributed equally.

Received 20 July 2020

Revised 08 September 2020

Accepted 08 December 2020

Check for updates

(C) Author(s) (or their employer(s)) 2020. Re-use permitted under CC BY-NC. No commercial re-use. See rights and permissions. Published by BMJ.

\section{Guangdong Provincial}

People's Hospital, Guangdong Academy of Medical Sciences, Guangzhou, Guangdong, China

Correspondence to Professor Qingshan Geng; gengqingshan@gdph.org.cn

\section{ABSTRACT}

Background The coexistence of multiple chronic conditions is very common in cardiovascular disease (CVD). However, the prevalence of CVD multimorbidity in China and its influence on life satisfaction have not been reported. This study aimed to investigate the proportions of 12 chronic comorbid diseases in CVD and the associations of multimorbidity with life satisfaction in patients with CVD. Methods We conducted a cross-sectional study in a nationally representative sample of 3478 participants with CVD aged 45 years or more who participated in the China Health and Retirement Longitudinal Study 2015. Correlations of multimorbidity with 12 chronic diseases in CVD and life satisfaction were investigated using logistic regression models, after adjusting for 12 covariates.

Results The proportion of multimorbidity among participants with CVD was $93.3 \%$ (89.4\% for middleaged adults and $95.4 \%$ for older adults; $92.9 \%$ for men and $93.5 \%$ for women). The proportion of participants with CVD multimorbidity who were dissatisfied with life was $11.2 \%$, significantly higher than those without any chronic diseases $\left(\chi^{2}=5.147, p=0.023\right)$. Life satisfaction in patients with CVD decreased with increased number of comorbidities $\left(\chi^{2}=45.735, p<0.001\right)$. Kidney disease (OR=1.933, 95\% Cl: 1.483 to 2.521), memory-related diseases (MRDs) (OR=1.695, 95\% Cl: 1.149 to 2.501) and dyslipidaemia (OR=1.346, 95\% Cl: 1.048 to 1.729$)$ were significantly associated with reduced life satisfaction when adjusting for 12 covariates.

Conclusions In this nationally representative crosssectional study, life satisfaction was reduced by multimorbidity of CVD. Kidney disease had the greatest influence on life satisfaction in patients with CVD, followed by dyslipidaemia and MRDs. Our study emphasises the importance of preventing of chronic diseases in adults with CVD.

\section{INTRODUCTION}

Cardiovascular disease (CVD) is a major public health problem that has reached epidemic proportions in China and other countries. China now faces enormous pressure because of its ageing population. The ageing of the Chinese population is accelerating; in 2015, 220 million people in China were age $\geq 60$ years old. ${ }^{1}$ Age-related changes
Strengths and limitations of this study

- Participants recruited in China Health and Retirement Longitudinal Study were nationally representative of Chinese middle-aged and older adults

- To the best of our knowledge, this is the first nationally representative analysis of the association of cardiovascular disease multimorbidity with life satisfaction.

- Life satisfaction was investigated using only one question; therefore, certain aspects of life satisfaction could not be measured.

- This study only included 12 of the most common chronic diseases.

in cardiovascular structure, physiology and biology increase the susceptibility to CVD. ${ }^{2}$ It was reported that more than $70 \%$ of adults develop CVD by the age of $70 .{ }^{3}$ The WHO estimated that 20 million people died of CVD in 2015. In China, CVD is becoming more prevalent and it was the main cause of death in $2015 .{ }^{5}$ With advancing medical technology and population ageing, increasingly more adults with chronic CVD survive to older ages. Multimorbidity, the coexistence of multiple chronic conditions in an individual, is very common in $\mathrm{CVD},{ }^{6}$ and it is reported that more than $50 \%$ CVD patients have at least one additional disease. ${ }^{7}$

Except for coexisting multiple CVDs, CVD coexisting with non-CVD morbidities can substantially impact the clinical features, diagnosis, management and outcome of most older patients. ${ }^{8}$ The WHO has pointed out that approximately $13 \%$ of CVD deaths are associated with diabetes, ${ }^{9}$ hypertension ${ }^{10}$ and dyslipidaemia, ${ }^{11}$ which are recognised as the most common occurrences of multimorbidity with CVD.

The presence of multiple chronic conditions greatly increases the complexity of managing patients with CVD and the burden 
of the disease. ${ }^{12}$ Patients with CVD who have multiple conditions have greater difficulty with activities of daily living and a poor health status. ${ }^{13}$ It is reported that the quality of life can significantly be affected by multimorbidity among CAD patients. ${ }^{14}$ Life satisfaction is a construct of the subjective well-being related to how people evaluate the quality of their lives, ${ }^{12}{ }^{15}$ and it is increasingly recognised as an important determinant of health. ${ }^{16}$ Therefore, an investigation of the life satisfaction in patients with CVD who have multiple chronic diseases is a feasible way of understanding their quality of life and well-being to improve life satisfaction among patients with CVD. Although life satisfaction has been reported to be associated with increasing proportions of multimorbidity accumulation, ${ }^{17}$ no studies on the association of life satisfaction and inpatients with CVD who have multiple chronic diseases have been conducted. The aim of the present was to investigate the association of life satisfaction and chronic disease comorbidity with CVD (referred to as CVD multimorbidity) in a representative Chinese national sample.

\section{METHODS}

\section{Study sample}

The China Health and Retirement Longitudinal Study (CHARLS) is an ongoing health survey of the Chinese population. ${ }^{18}$ Conducted by the National School for Development (China Center for Economic Research), it is a large-scale, multistage and nationally representative of the 30 provinces of China. Participants are investigated face to face in their homes using questionnaires via computer-assisted personal interviewing technology. All respondents signed informed consent forms.

We investigated data of 3478 participants with records of CVD, life satisfaction and age in the CHARLS 2015 database.

\section{Life satisfaction}

Life satisfaction was self-rated as 'completely satisfied', 'very satisfied', 'somewhat satisfied', 'not very satisfied' or 'not at all satisfied', using the following question: "Please think about your life as a whole. How satisfied are you with your life?". People who responded 'completely satisfied', 'very satisfied' or 'somewhat satisfied' were classified as satisfied; the remainder were classified as unsatisfied. This one-dimensional life satisfaction measurement was based on the general perception of life, rather than with special aspects of life, and is commonly used in largescale, nationwide surveys in China. ${ }^{19}$

\section{CVD and other chronic diseases}

CVD comprises heart disease and stroke, and it was determined if the respondent had it in face-to-face interviews using the following question: "Have you ever been diagnosed with heart attack, coronary heart disease, angina, congestive heart failure, or other heart problems, or stroke by a doctor?". Participants reporting heart disease or stroke were defined as having CVD. Researchers checked medications that these participants were taking or the receipts in their clinical records for those who reported CVD.

Comorbid diseases included hypertension, dyslipidaemia (elevation of triglyceride, total cholesterol, lowdensity lipoprotein or high-density lipoprotein levels), hyperglycaemia including diabetes, cancer excluding minor skin cancers, lung disease (eg, chronic bronchitis or emphysema) excluding lung tumours or cancer, liver disease excluding fatty liver disease, liver tumours or cancer, kidney disease excluding kidney tumour or cancer, stomach or other digestive tract disease excluding digestive tumour or cancer, emotional, nervous or psychiatric disorder, memory-related diseases (MRDs), arthritis or rheumatism (AR) and asthma. This information was acquired using the same method as for CVD.

\section{Covariate assessment}

Based on previous analyses of life satisfaction, we included several relevant covariates in our study: age, sex, marital status, place of residence, smoking, alcohol consumption, social activity, older age insurance, health insurance, sleep duration(hours) and nap duration (minutes). These were all collected using standardised questionnaires during the interviews. Age was classified as middle age ( $<60$ years) and older age ( $\geq 60$ years). Marital status was categorised as married (married and living as married), divorced or widowed and single (never married and separated). Place of residence was categorised as family housing and other housing (nursing home or hospital). Smoking and alcohol consumption were both categorised as yes (current smoking or alcohol consumption), former (former but not current smoking or alcohol consumption) and no (never smoking or alcohol consumption). For social activity, the inactive group was defined as those with no reported physical activity, interaction with friends such as playing chess or cards, providing help to people they do not live with, engaging in sports, belonging to a community-related organisation, charity work, caring for a sick or disabled adult, attending courses or use of the internet in the previous month. Older age insurance and health insurance were classified as yes and no. Sleep duration and nap duration were average times per day in the past month.

\section{Statistical analyses}

Mean (SD) or median (IQR) are used for continuous variables and frequency (percentage) for categorical variables. The $\chi^{2}$ test was used for comparing categorical variables and the Wilcoxon rank-sum test was used for comparing continuous variables. Association of life satisfaction with the number of comorbid chronic diseases in CVD was analysed via linear-by-linear $\chi^{2}$ test. Logistic regression was used in the association analysis of sex (or age), number of chronic diseases comorbid with CVD and life satisfaction. Associations of CVD multimorbidity with life satisfaction were analysed via logistic regression 
Table 1 Multimorbidity among patients with cardiovascular disease in China grouped by age and sex

\begin{tabular}{|c|c|c|c|c|c|c|c|c|c|}
\hline \multirow[b]{2}{*}{ Chronic disease } & \multirow[b]{2}{*}{ Total } & \multicolumn{2}{|l|}{ Age } & \multirow[b]{2}{*}{$\chi^{2}$} & \multirow[b]{2}{*}{ P value } & \multicolumn{2}{|l|}{ Sex } & \multirow[b]{2}{*}{$\chi^{2}$} & \multirow[b]{2}{*}{$P$ value } \\
\hline & & $\begin{array}{l}\text { Middle* }^{*} \\
(n=1251)\end{array}$ & $\begin{array}{l}\text { Older† } \\
(n=2227)\end{array}$ & & & $\begin{array}{l}\text { Male } \\
(n=1449)\end{array}$ & $\begin{array}{l}\text { Female } \\
(n=2029)\end{array}$ & & \\
\hline Dyslipidaemia & $1161(33.4)$ & $398(31.8)$ & 763 (34.3) & 2.156 & 0.142 & $503(34.7)$ & 658 (32.4) & 1.983 & 0.159 \\
\hline High blood sugar & $641(18.4)$ & $191(15.3)$ & $450(20.2)$ & 12.997 & $<0.001$ & $254(17.5)$ & $387(19.1)$ & 1.341 & 0.247 \\
\hline Liver disease & $402(11.6)$ & $158(12.6)$ & $244(11)$ & 2.194 & 0.139 & $174(12)$ & $228(11.2)$ & 0.492 & 0.483 \\
\hline Kidney disease & $611(17.6)$ & $212(16.9)$ & 399 (17.9) & 0.520 & 0.471 & $287(19.8)$ & $324(16)$ & 8.600 & 0.003 \\
\hline Digestive disease & $1445(41.5)$ & $530(42.4)$ & $915(41.1)$ & 0.540 & 0.462 & $506(34.9)$ & 939 (46.3) & 44.906 & $<0.001$ \\
\hline ENP disorder & $175(5)$ & 52 (4.2) & $123(5.5)$ & 3.130 & 0.077 & 61 (4.2) & $114(5.6)$ & 3.511 & 0.061 \\
\hline Totalł & 3244 (93.3) & 1119 (89.4) & 2125 (95.4) & 45.52 & $<0.001$ & 1346 (92.9) & 1898 (93.5) & 0.573 & 0.449 \\
\hline
\end{tabular}

Data are expressed as numbers (percentages).

*Middle-aged adults, $\geq 45$ to $<60$ years old.

†Older adults, $\geq 60$ years old.

$\ddagger$ Total is a multimorbid state with the existence of any one chronic disease.

$\mathrm{AR}$, arthritis or rheumatism; ENP, emotional, nervous or psychiatric; MRD, memory-related disease.

analysis using three models with varying degrees of covariate adjustment. We checked model assumptions for all the analyses. Participants with missing data were omitted from the analysis. All statistical analyses were conducted using IBM SPSS V.20. Two-sided $\mathrm{p}<0.05$ were considered statistically significant.

\section{RESULTS}

Among the 3478 participants aged 45-92 years (mean age 63.06 years, SD, 9.88; $41.7 \%$ men) in this study, $36 \%$ $(n=1251)$ were middle aged $(\geq 45$ to $<60$ years $)$ and $64 \%$ $(\mathrm{n}=2227)$ were older than 60 years.

\section{CVD multimorbidity}

Among the 12 chronic diseases, the number of comorbidities with CVD ranged from 0 to 11 ; median (IQR) values were $3(2,4)$ for all adults, $2(1,4)$ for middle-aged adults and $3(2,4)$ for older adults. In total, $17.1 \%(n=594)$ of the participants with CVD had only one comorbid chronic disease, $22.3 \% \quad(n=777)$ had two comorbid chronic diseases and 21.4\% ( $\mathrm{n}=746)$ had three comorbid chronic diseases; $16.6 \% \quad(n=579), 9.1 \% \quad(n=316), 3.9 \%$ $(\mathrm{n}=137), 1.6 \% \quad(\mathrm{n}=57)$ and $1.1 \%(\mathrm{n}=38)$ of participants with CVD had 4, 5, 6, 7 and 8 comorbid chronic diseases, respectively.

Table 1 lists the age and sex distribution of the 12 chronic diseases among adults with CVD. The proportion of participants with CVD who had multimorbidity was $93.3 \%$, $(89.4 \%$ for middle-aged adults and $95.4 \%$ for older adults, $92.9 \%$ for men and $93.5 \%$ for women).
The proportions of multimorbidity were higher in older adults than in the middle-aged adults $\left(\chi^{2}=45.52\right.$, $\mathrm{p}<0.001)$, but there was no significant difference by sex $\left(\chi^{2}=0.573, \mathrm{p}=0.449\right)$. Hypertension $(56.1 \%)$, AR $(53.9 \%)$ and digestive diseases $(41.5 \%)$ were the top three chronic disease comorbidities with CVD. Compared with middleaged adults who had CVD, older adults had significantly higher proportions of multimorbidity involving hypertension $\left(\chi^{2}=39.929, \mathrm{p}<0.001\right)$, hyperglycaemia $\left(\chi^{2}=12.997\right.$, $\mathrm{p}<0.001)$, chronic lung disease $\left(\chi^{2}=36.396, \mathrm{p}<0.001\right)$, MRD $\left(\chi^{2}=13.381, \mathrm{p}<0.001\right), \operatorname{AR}\left(\chi^{2}=6.432, \mathrm{p}<0.001\right)$ and asthma $\left(\chi^{2}=19.939, p<0.001\right)$. Compared with men, women had lower proportions of multimorbidity with hypertension $\left(\chi^{2}=6.286, \mathrm{p}=0.003\right)$, chronic lung disease $\left(\chi^{2}=5.449, \mathrm{p}=0.02\right)$, kidney disease $\left(\chi^{2}=8.6, \mathrm{p}<0.001\right)$ and asthma $\left(\chi^{2}=9.862, \mathrm{p}=0.002\right)$, and higher proportions with cancer $\left(\chi^{2}=10.806, p=0.001\right)$, digestive disease $\left(\chi^{2}=44.906\right.$, $\mathrm{p}<0.001)$ and AR $\left(\chi^{2}=90.122, \mathrm{p}<0.001\right)$.

Age-specific and sex-specific proportions of multimorbidity and summed proportions of multimorbidity in participants with CVD are shown in figure 1. Most common was three comorbid chronic diseases in older adults with multimorbidity (22.9\%), followed by two comorbid chronic diseases in middle-aged adults with multimorbidity $(22.6 \%)$, shown in figure $1 \mathrm{~A}$. Older participants had significantly higher summed proportions of multimorbidity with more than one chronic disease (figure 1C). The proportion of multimorbidity with only one chronic disease in men was significantly higher than that in women $\left(\chi^{2}=7.283\right.$, 

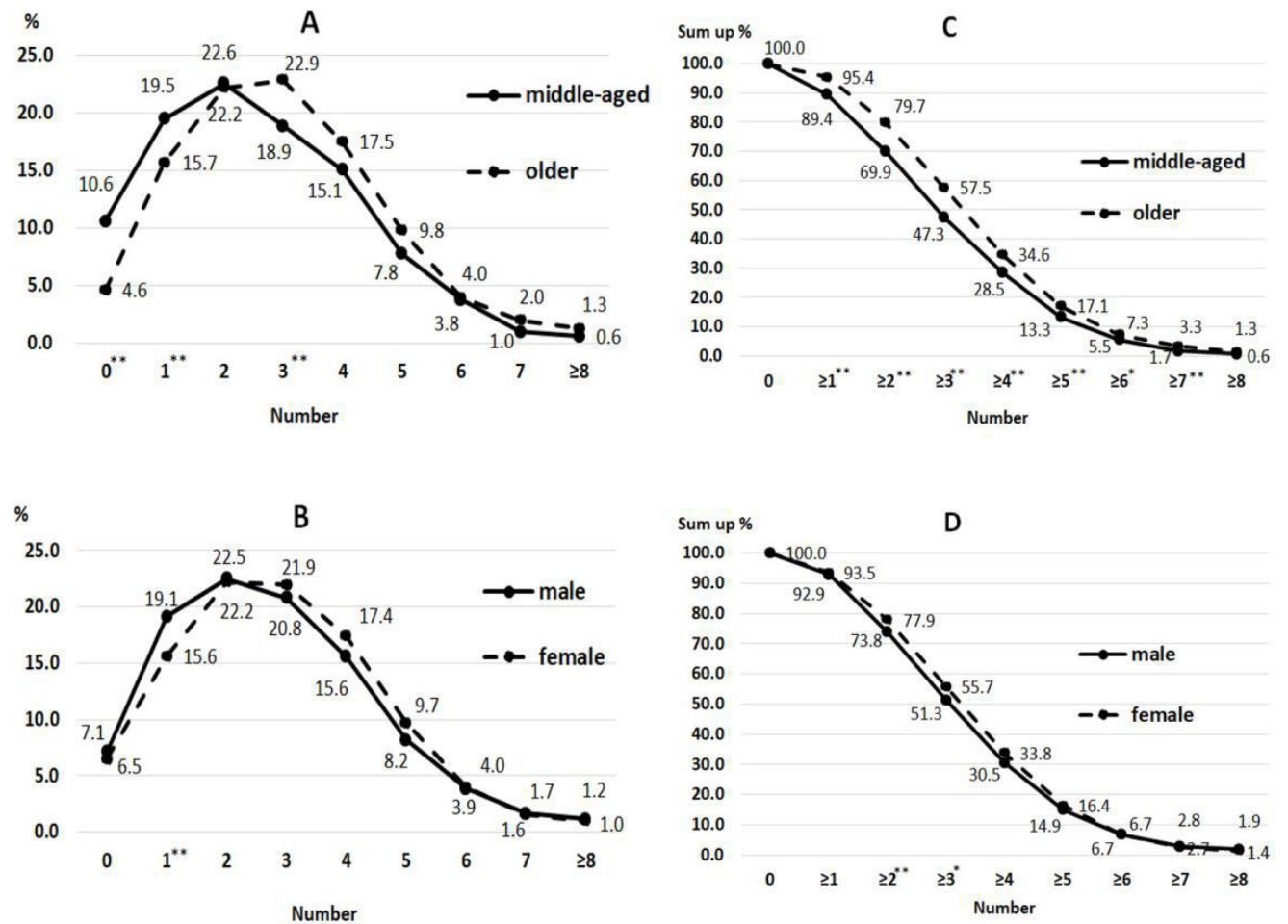

Figure 1 Proportion of multimorbidity with the indicated number of comorbidities grouped by age (A) and sex (B). Summed proportions of multimorbidity with the indicated number of comorbidities grouped by age (C) and sex (D). All participants had cardiovascular disease $\left({ }^{*} \mathrm{p}<0.05,{ }^{* *} \mathrm{p}<0.01\right)$.

$\mathrm{p}=0.007$ ) (figure $1 \mathrm{~B}$ ). However, the summed proportion of multimorbidity with two $\left(\chi^{2}=6.632, \mathrm{p}=0.01\right)$ and three $\left(\chi^{2}=4.093, \mathrm{p}=0.043\right)$ chronic diseases in men was significantly lower than that in women $\left(\chi^{2}=6.632\right.$, $\mathrm{p}=0.01$ ) (figure 1D). The number of comorbidities accompanying CVD increased with age in both men and women among middle-aged adults $(F=5.123$, $\mathrm{p}<0.001)$ and older adults $(F=5.123, \mathrm{p}<0.001)$.

\section{Association of CVD multimorbidity with life satisfaction}

The proportion of all participants who were dissatisfied with life was $10.9 \%$. The proportion of life dissatisfaction among participants with CVD and without multimorbidity was $6.4 \%$, and this was $11.2 \%$ among their counterparts with multimorbidity, with significant differences $\left(\chi^{2}=5.147, \mathrm{p}=0.023\right)$. The mean number of comorbidities was 2.76 (SD, 1.67) among participants who were satisfied with their life and 3.31 (SD, 1.87) among those who were dissatisfied with their life; this difference was significant $(p<0.001)$. We also compared life satisfaction among different numbers of chronic disease comorbidities with CVD. We found a significant association of decreased life satisfaction with increased number of comorbid diseases (figure 2A). The same sequences were found in both men and women (figure 2B) and both middle-aged and older adults (figure $2 \mathrm{C}$ ).

We also analysed the association of sex, number of chronic diseases comorbid with CVD and life satisfaction (table 2, model 1), and the association of age, number of chronic diseases comorbid with CVD and life satisfaction (table 2, model 2). In model 1, the interaction of sex and number of chronic diseases comorbid with CVD was not statistically significant $(p=0.580)$. After removing the interaction, no significant difference was found in life satisfaction between male and female sex $(\mathrm{OR}=1.179,95 \% \mathrm{CI}$ : 0.945 to 1.472$)$. The association of number of chronic diseases comorbid with CVD and life satisfaction was significant, with $\mathrm{p}<0.001$. Compared with no chronic disease comorbidity with CVD, with four CVD multimorbidities, the association with life satisfaction was significant, with $\mathrm{OR}=1.992(95 \% \mathrm{CI} 1.116$ to 3.558$)$. The strength of the association was larger with the increased number of CVD multimorbidities. The same trend for the association of the number of chronic disease comorbidities with CVD and life satisfaction was found in model 2. In model 2, the interaction of age and number of chronic disease comorbidities with CVD was not statistically significant $(\mathrm{p}=0.392)$. After removing the interaction, age $(\mathrm{OR}=0.721,95 \% \mathrm{CI} 0.578$ to 0.899$)$ ) and number of chronic disease $(\mathrm{p}<0.001)$ comorbidities with CVD and life satisfaction were both significant.

The association of one chronic disease (and only one chronic disease) comorbidity with CVD was assessed via logistic regression analysis, either unadjusted (model 1) or adjusted for covariates (models 2 and 3) (table 3). Three comorbidities were significantly associated with reduced life satisfaction in model 3: kidney disease 


\section{A}

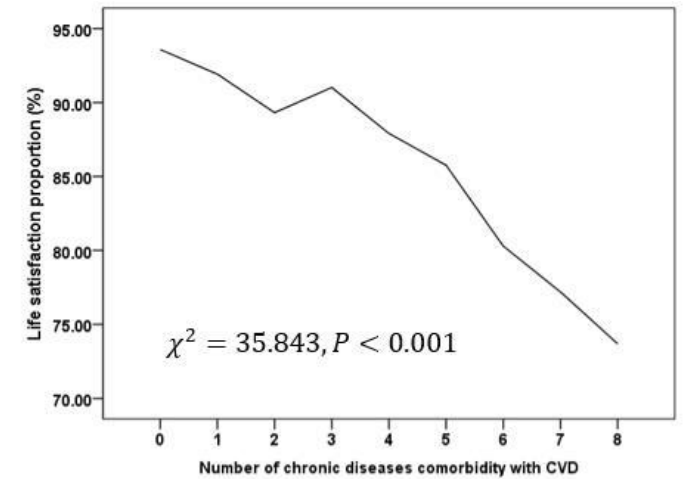

B

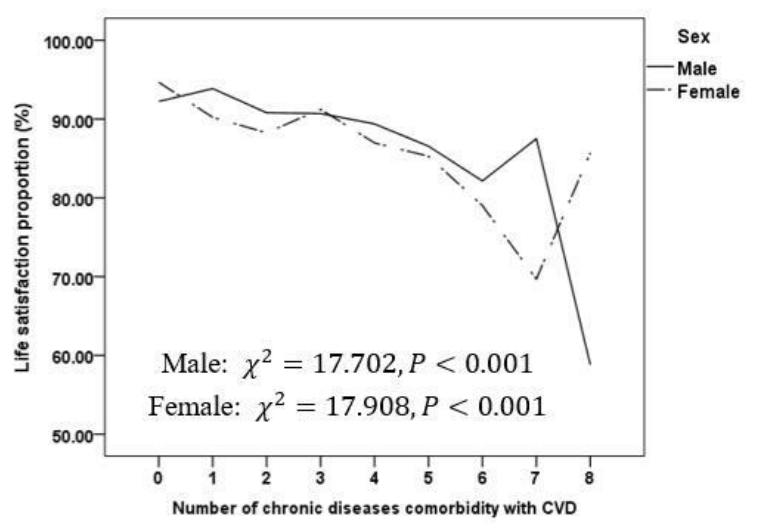

C

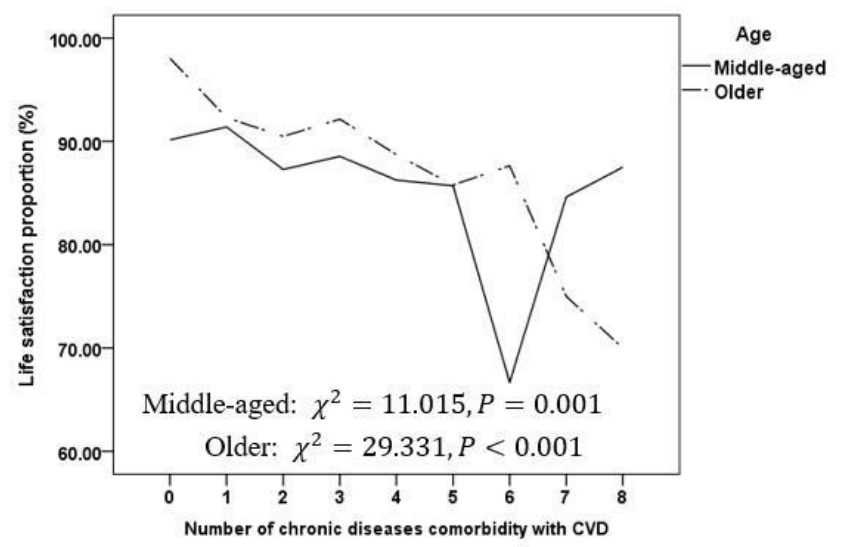

Figure 2 Life satisfaction among participants with different numbers of chronic diseases comorbid with cardiovascular disease (A) and sex-specific (B) and age-specific (C) associations.

(OR=1.933, 95\% CI 1.483 to 2.521), MRD (OR=1.695, $95 \% \mathrm{CI} 1.149$ to 2.501$)$ and dyslipidaemia $(\mathrm{OR}=1.346$, 95\% CI 1.048 to 1.729). Life satisfaction differed between middle-aged adults and older adults and between men and women (figure 3).

\section{DISCUSSION}

\section{Summary}

This analysis was based on the complete national population of China, using data of the CHARLS 2015. In this large cross-sectional study of a nationally representative sample, we found that CVD multimorbidity is highly prevalent in China. Although primarily associated with older adults, multimorbidity also occurs in a substantial number of middle-aged adults. ${ }^{20}$

In our study, we found that life satisfaction in patients with CVD decreased as the number of comorbidities with other chronic diseases increased. For older adults, we found that CVD with three or more comorbidities was more prevalent.

This study showed that kidney disease, dyslipidaemia and MRD were significantly correlated with reduced life satisfaction. These associations were independent of age, sex, marital status, place of residence, smoking, alcohol consumption, social activity, older age insurance, health insurance, sleep duration and nap duration. Our study emphasises the importance of preventing of chronic diseases in adults with CVD.

We found that the median number of comorbidities in older adults was three and two in middle-aged adults. The number of comorbidities increased with age in both men and women.

As a novel finding, our study revealed that the summed proportion of multimorbidity of two and three chronic diseases in women was significantly higher than those in men. Reasons for this difference include the higher exposure of women to common risk factors for chronic diseases and sex inequality in terms of access to healthcare. ${ }^{21}$

To the best of our knowledge, this is the first nationally representative analysis of the association of CVD multimorbidity with life satisfaction. This study revealed that $11.2 \%$ of participants with CVD multimorbidity were dissatisfied with their life, which was significantly higher than the proportion in those without other chronic diseases. The proportion of adults who were satisfied with their life decreased as the number of comorbidities increased, which was in line with the findings of previous studies. ${ }^{22}{ }^{23}$ The same trend was found in both men and women and both middle-aged adults and older adults. We also found that with four and more chronic disease comorbidities with CVD four and more, the risk of life dissatisfaction was significantly higher than with no CVD comorbidities. A heavy treatment burden and poor prognosis may be important reasons for this result. ${ }^{24}$ Another interesting finding was that the risk of life dissatisfaction with each number of CVD multimorbidities was higher in middle-aged adults than older adults. Age reportedly negatively associated with life satisfaction. ${ }^{25}$ Old age is associated with higher levels of happiness and life satisfaction, which is in line with our results. ${ }^{26}$ Taken together, these studies as well as our findings underscore the importance of preventing multiple chronic diseases in patients with CVD, especially middle-aged adults, as a simple way to promote life satisfaction.

The most important finding was that 3 (dyslipidaemia, kidney disease and MRD) of 12 chronic diseases were significantly correlated with reduced life satisfaction. Kidney disease could significantly increase the risk of life dissatisfaction by $193.3 \%$ for all participants, followed by dyslipidaemia $(\mathrm{OR}=1.346)$ and MRD $(\mathrm{OR}=1.695)$. Kidney disease is also the only single chronic disease that showed 
Table 2 Association of the number of multimorbid conditions in cardiovascular disease, sex (age) and life satisfaction

\begin{tabular}{|c|c|c|c|c|c|c|}
\hline Model & Variables & No & B & P value & OR & $95 \% \mathrm{Cl}$ \\
\hline \multirow[t]{9}{*}{ Model 1} & Gender & & & & & \\
\hline & Male & 1449 & Ref & & & \\
\hline & Number of CVD multimorbidity & & & & & \\
\hline & $\mathrm{n}=0$ & 234 & Ref & & & \\
\hline & $n=2$ & 777 & 0.554 & 0.057 & 1.741 & 0.984 to 3.08 \\
\hline & $n=3$ & 746 & 0.359 & 0.225 & 1.432 & 0.802 to 2.559 \\
\hline & $n=4$ & 579 & 0.689 & 0.02 & 1.992 & 1.116 to 3.558 \\
\hline & $n=5$ & 316 & 0.876 & 0.005 & 2.401 & 1.303 to 4.423 \\
\hline & $\mathrm{n}=6$ & 137 & 1.272 & $<0.001$ & 3.568 & 1.823 to 6.985 \\
\hline \multirow[t]{9}{*}{ Model 2} & Age & & & & & \\
\hline & Middle-aged & 1251 & Ref & & & \\
\hline & Older & 2227 & -0.328 & 0.004 & 0.721 & 0.578 to 0.899 \\
\hline & Number of CVD multimorbidity & & & $<0.001$ & & \\
\hline & $\mathrm{n}=0$ & 234 & Ref & & & \\
\hline & $n=1$ & 594 & 0.300 & 0.328 & 1.350 & 0.739 to 2.465 \\
\hline & $n=2$ & 777 & 0.624 & 0.033 & 1.867 & 1.053 to 3.311 \\
\hline & $n=3$ & 746 & 0.448 & 0.132 & 1.565 & 0.873 to 2.805 \\
\hline & $\mathrm{n}=4$ & 579 & 0.777 & 0.009 & 2.175 & 1.215 to 3.896 \\
\hline
\end{tabular}

a significant association with life satisfaction when only considering one chronic disease comorbidity with GVD. Previous reports emphasise the importance of improving the care of patients with CVD who have chronic kidney disease. ${ }^{27}$ Reduced kidney function increases the risk of cardiovascular events and death, ${ }^{28}$ and patients with both cardiovascular and kidney diseases have a higher risk of death than those with either alone. ${ }^{29}$ The association of dyslipidaemia comorbidity with CVD and life satisfaction in women was higher than that in men, which is clinically noteworthy. Because dyslipidaemia is a prominent risk factor for CVD, ${ }^{30}$ women with a history of CVD should maintain a low-density lipoprotein cholesterol level $<100 \mathrm{mg} / \mathrm{dL}$ and preferably $<70 \mathrm{mg} / \mathrm{dL}$. ${ }^{31}$ Treatment of dyslipidaemia is essential for preventing CVD. ${ }^{32}$

\section{Comparison with existing literature}

This study showed that more than half of older adults had multimorbidity with three chronic diseases and with two chronic diseases in more than half of middleaged adults. This finding was in line with the results of a previous study. ${ }^{14}$ The rate of CVD multimorbidity in
China is $93.3 \%$, and this is slightly higher in Northeast China $(96.17 \%) .^{33}$

In our study, as in other research, ${ }^{34}$ the number of comorbidities increased with age in men and women. Whereas multimorbidity can develop at all ages, the number, complexity and diversity of comorbid conditions usually increase with advancing age. ${ }^{35}$ This study showed that the proportion of men with CVD who had one chronic comorbid disease was higher than that of their female counterparts. However, although there was no significant difference, the proportion of women with CVD who had two and more comorbidities was higher than that in their male counterparts, which is in agreement with previous studies. ${ }^{36} 37$

In this study, we used a one-dimensional model to estimate life satisfaction. A one-dimensional model, measuring overall satisfaction in life with a single question, is commonly used in large-scale, nationwide surveys and international surveys, and this type of model has been proven to be credible and reliable. ${ }^{38}$ Compared with a multidimensional model, one-dimensional model 


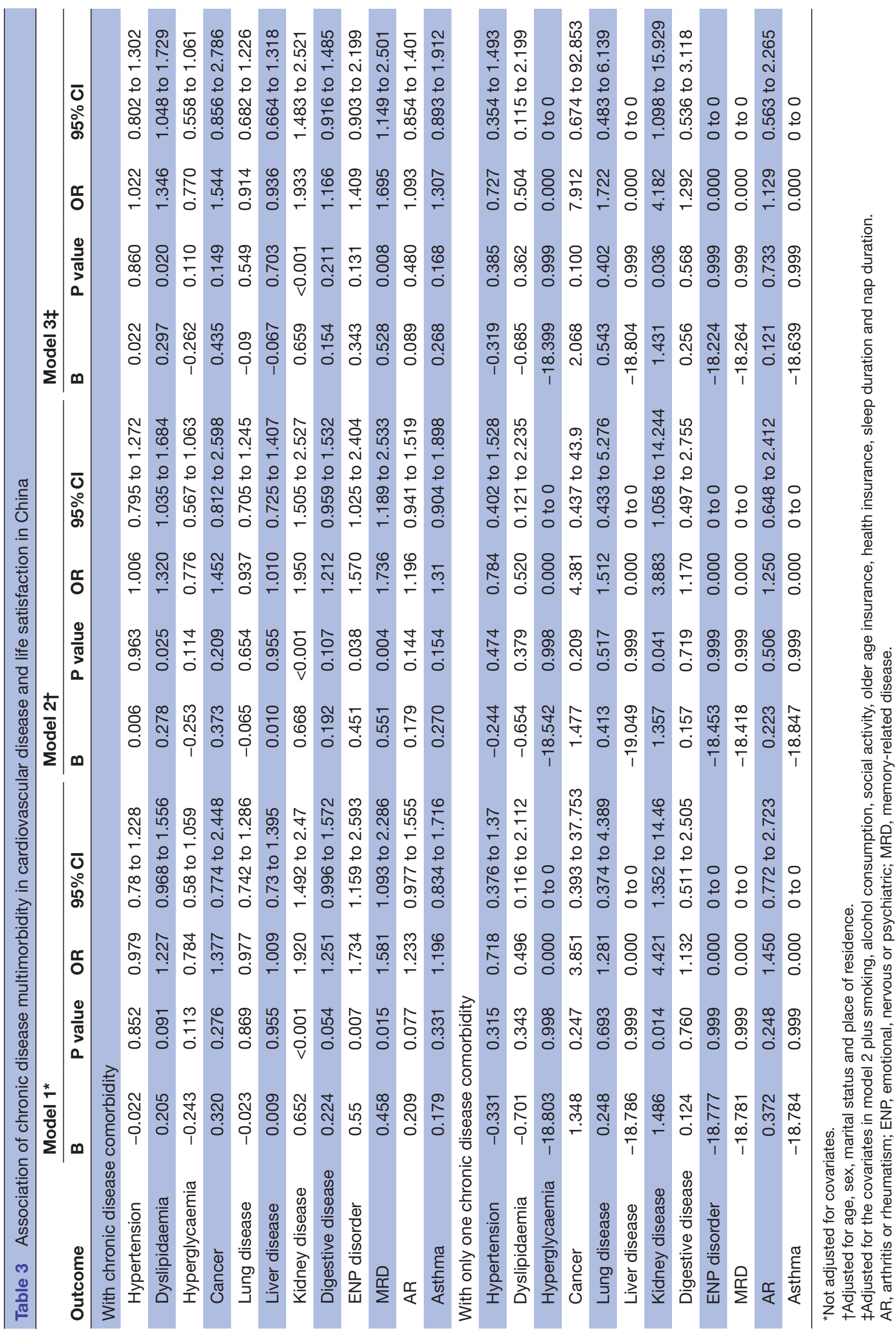



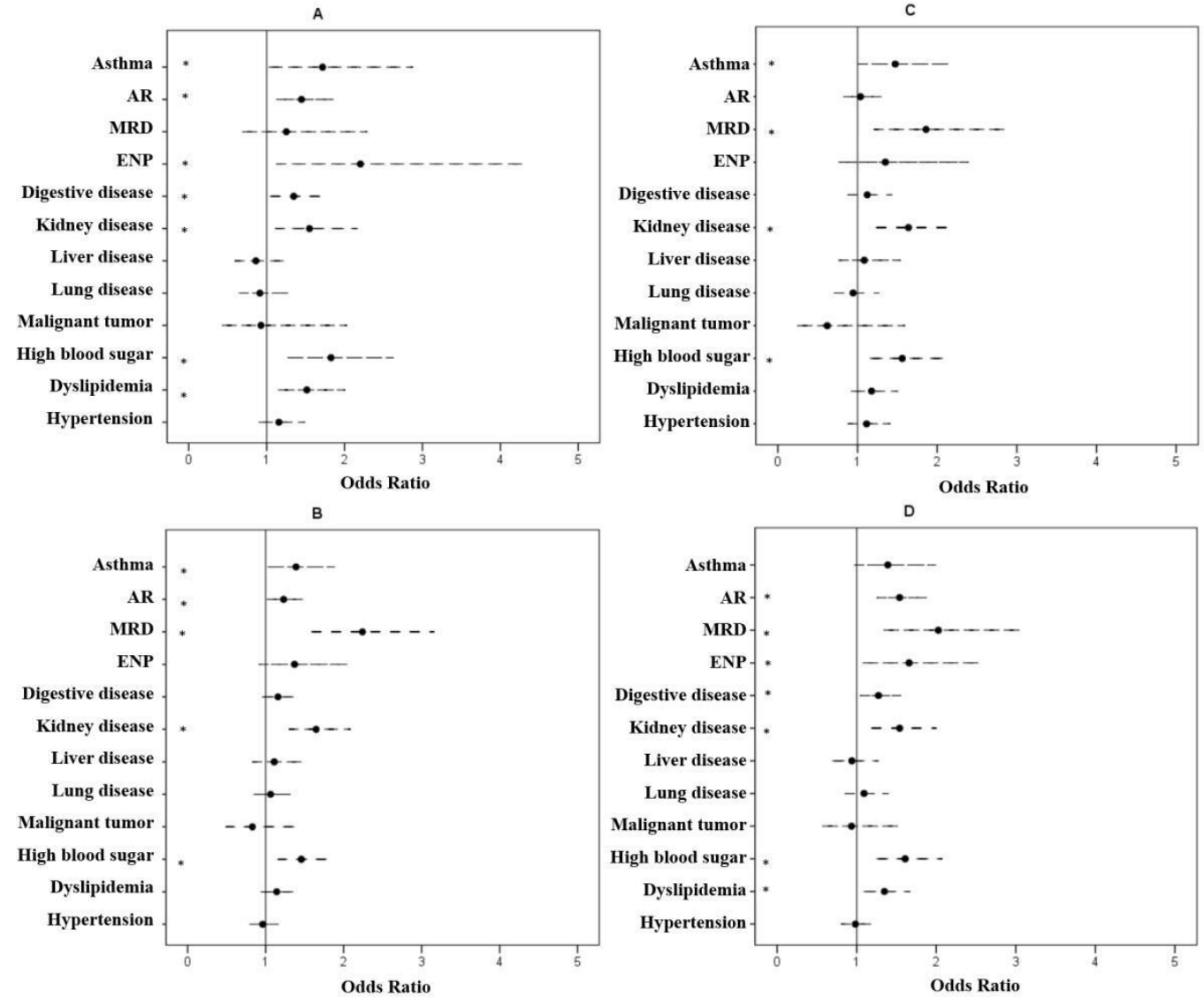

Figure 3 Association of cardiovascular disease multimorbidity with life satisfaction grouped by age (A: middle-aged adults, B: older adults) and sex (C: men, D: women). ORs were calculated after adjusting for age, sex, marital status, place of residence, smoking, alcohol consumption, social activity, older age insurance, health insurance, sleep duration and nap duration ( $\left.{ }^{*} \mathrm{p}<0.05\right)$. $\mathrm{AR}$, arthritis or rheumatism; ENP, emotional, nervous or psychiatric; MRD, memory-related disease.

is based on the perception of general satisfaction with life rather than life satisfaction with respect to certain aspects. One-dimensional model of life satisfaction had been shown to effectively predict mortality, hospitalisation and overall health. ${ }^{39}$

Our previous study pointed that comorbidity with CVD and depression could significantly increase the risk of MRD. ${ }^{40}$ We revealed in this study that the comorbidity of CVD and MRD could significantly increase the risk of life dissatisfaction by $169.5 \%$. Although a previous study reported a significant positive relationship between subjective memory and overall well-being in older adults, ${ }^{41}$ our study was the first to investigate the association of MRD comorbidity with CVD and lower life satisfaction.

\section{Limitations}

Although this study is a representative sample of China, some limitations remain. First, chronic diseases including CVD were all self-reported, which has been proven to have poor sensitivity but good specificity and positive predictive values $^{42}$ but might nevertheless be prone to information error. Second, the data were obtained from a nationwide CHARLS survey. Only a single question was used to measure overall life satisfaction among individuals with different occupations. ${ }^{43}$ This approach does not allow us to develop a more comprehensive understanding of which area of life respondents are dissatisfied with. ${ }^{45}$ As this is a cross-sectional study, only association of life satisfaction and chronic disease comorbidity in CVD could be revealed. Although 11 covariates were adjusted, several others were not included, such as personality and economic confounders.

\section{Implications for research and practice}

CVD multimorbidity is prevalent among middle-aged adults and older adults in China, which is a major public health concern. The high prevalence of CVD multimorbidity may reflect the age-related decline in immune function, and hence the increased vulnerability of older adults and middle-aged adults to chronic diseases. ${ }^{45} \mathrm{We}$ also investigated whether life satisfaction declined when chronic disease comorbidity with CVD increased; we found that this decline was worse for middle-aged adults than older adults. This calls attention to the importance of preventing of other chronic diseases among middle-aged adults with CVD and not only their older counterparts.

Our study showed that dyslipidaemia, kidney disease and MRD were significantly associated with reduced life satisfaction, independent of age, sex, marital status, place of residence, smoking, alcohol consumption, social activity, older age insurance, health insurance, sleep duration and nap duration. Although we were unable to 
determine a causal link between CVD multimorbidity and reduced life satisfaction, our findings regarding this association are valuable. Life satisfaction is not only a measure of health and quality of life but also a reflection of hope and confidence in life. ${ }^{46} 47$

Our study emphasises the importance of preventing of chronic diseases in adults with CVD. Prevention and treatment of chronic disease comorbidity in CVD warrants further research in prospective cohort studies or clinical trials. Future research should further explore the issues associated with or responsible for higher levels of life satisfaction among older adults with CVD and comorbid kidney disease, dyslipidaemia and MRD.

Correction notice This article has been corrected since it was first published. The correct author affiliation of the article is 'Guangdong Provincial People's Hospital, Guangdong Academy of Medical Sciences, Guangzhou, Guangdong,China'.

Acknowledgements We thank the participants and staff of the China Health and Retirement Longitudinal Study (CHARLS) team for their valuable contributions.

Collaborators Not Applicable.

Contributors GL, YX and QG designed and performed the research study. GL, YX and YL wrote original draft, curation data. YX analysed the data. YL and SW performed formal analysis and provided comments. QG performed conceptualisation and methodology, accessed to funds, provided guidance and comments. These authors critically revised the manuscript and agreed to the final version.

Funding This work was supported by the Medical Scientific Research Foundation of Guangdong Province of China (grant number A2020008), the High-level Hospital Construction Project of Guangdong Provincial People's Hospital of China (grant number DFJH201811 and KJ012019431) and the Scientific Research Foundation of Health Economics Association of Guangdong Province of China (grant number 2019-WJMF-02 and 2020-WJZD-12).

Competing interests None declared.

Patient and public involvement Patients and/or the public were not involved in the design, or conduct, or reporting, or dissemination plans of this research.

Patient consent for publication Obtained.

Ethics approval All procedures performed in studies involving human participants were in accordance with the ethical standards of the institutional and/or national research committee and with the 1964 Declaration of Helsinki and its later amendments or comparable ethical standards. Ethics approval for data collection in the CHARLS was obtained from the Biomedical Ethics Review Committee of Peking University (IRB00001052-11015).

Provenance and peer review Not commissioned; externally peer reviewed.

Data availability statement Data are available upon reasonable request. The datasets generated and analysed during the current study are available from the corresponding author on reasonable request.

Open access This is an open access article distributed in accordance with the Creative Commons Attribution Non Commercial (CC BY-NC 4.0) license, which permits others to distribute, remix, adapt, build upon this work non-commercially, and license their derivative works on different terms, provided the original work is properly cited, appropriate credit is given, any changes made indicated, and the use is non-commercial. See: http://creativecommons.org/licenses/by-nc/4.0/.

ORCID iDs

Guihao Liu http://orcid.org/0000-0001-5370-1474

Yunlian Xue http://orcid.org/0000-0002-9987-5004

\section{REFERENCES}

1 Jiang XQ, Du P. Report on China's population ageing and the elderly welfare facilities, 2015.

2 Forman DE, Rich MW, Alexander KP, et al. Cardiac care for older adults. Time for a new paradigm. J Am Coll Cardiol 2011;57:1801-10.
3 Tinetti ME, Fried TR, Boyd CM. Designing health care for the most common chronic condition--multimorbidity. JAMA 2012;307:2493-4.

4 WHO. Health topics. Available: http://www.who.int/en/; http://www. who.int/topics/cardiovascular diseases/en/

5 LY M, YZ W, Wang W, et al. Interpretation of the report on cardiovascular diseases in China (2017). Chin J Cardiovasc Med 2018;23:3-6.

6 Kleipool EE, Hoogendijk EO, Trappenburg MC, et al. Frailty in older adults with cardiovascular disease: cause, effect or both? Aging Dis 2018;9:489-97

7 Liu J, Ma J, Wang J, et al. Comorbidity analysis according to sex and age in hypertension patients in China. Int J Med Sci 2016;13:99-107.

8 Wenger NK, Doherty CL, Gurwitz JH, et al. Optimization of drug prescription and medication management in older adults with cardiovascular disease. Drugs Aging 2017;34:803-10.

9 Lehrke M, Marx N. Diabetes mellitus and heart failure. Am J Med 2017;130:S40-50.

10 Mendis S, Puska P, Norrving B. Global atlas on cardiovascular disease prevention and control. Geneva: World Health Organization, 2011.

11 Lavie CJ, McAuley PA, Church TS, et al. Obesity and cardiovascular diseases: implications regarding fitness, fatness, and severity in the obesity paradox. J Am Coll Cardiol 2014;63:1345-54.

12 Shad B, Ashouri A, Hasandokht T, et al. Effect of multimorbidity on quality of life in adult with cardiovascular disease: a cross-sectional study. Health Qual Life Outcomes 2017;15:240.

13 Violán C, Bejarano-Rivera N, Foguet-Boreu Q, et al. The burden of cardiovascular morbidity in a European Mediterranean population with multimorbidity: a cross-sectional study. BMC Fam Pract 2016;17:150.

14 Dunlay SM, Chamberlain AM. Multimorbidity in older patients with cardiovascular disease. Curr Cardiovasc Risk Rep 2016;10:1-9.

15 Dong $\mathrm{H}-\mathrm{J}$, Larsson B, Dragioti E, et al. Factors associated with life satisfaction in older adults with chronic pain (PainS65+). J Pain Res 2020;13:475-89.

16 Rosella LC, Fu L, Buajitti E, et al. Death and chronic disease risk associated with poor life satisfaction: a population-based cohort study. Am J Epidemiol 2019;188:323-31.

17 Calderón-Larrañaga A, Vetrano DL, Welmer A-K, et al. Psychological correlates of multimorbidity and disability accumulation in older adults. Age Ageing 2019;48:789-96.

18 Zhao Y, Hu Y, Smith JP, et al. Cohort profile: the China Health and Retirement Longitudinal Study (CHARLS). Int J Epidemiol 2014;43:61-8.

19 Wang XD, Wang XL. Manual on mental health assessment. 2nd edn. Chinese Magazine Agency of Mental Health, 1999: 75-9.

20 Barnett K, Mercer SW, Norbury M, et al. Epidemiology of multimorbidity and implications for health care, research, and medical education: a cross-sectional study. Lancet 2012;380:37-43.

21 Wang SB, D'Arcy C, Yu YQ, et al. Prevalence and patterns of multimorbidity in northeastern China: a cross-sectional study. Public Health 2015;129:1539-46.

22 Ge L, Ong R, Yap CW, et al. Effects of chronic diseases on healthrelated quality of life and self-rated health among three adult age groups. Nurs Health Sci 2019;21:214-22.

23 Marques A, Peralta M, Martins J, et al. Cross-sectional and prospective relationship between physical activity and chronic diseases in European older adults. Int J Public Health 2017;62:495-502.

24 Steeves JA, Shiroma EJ, Conger SA, et al. Physical activity patterns and multimorbidity burden of older adults with different levels of functional status: NHANES 2003-2006. Disabil Health J 2019;12:495-502.

25 Huang H, Liu S, Sharma A, et al. Factors associated with life satisfaction among married women in rural China: a cross-sectional study based on large-scale samples. Psychol Res Behav Manag 2018;11:525-33.

26 Grundy E, Murphy M. Coresidence with a child and happiness among older widows in Europe: does gender of the child matter? Popul Space Place 2018;24:e2102-e2102.13.

27 Glynn LG, Reddan D, Newell J, et al. Chronic kidney disease and mortality and morbidity among patients with established cardiovascular disease: a west of Ireland community-based cohort study. Nephrol Dial Transplant 2007;22:2586-94.

28 Sarnak MJ, Levey AS, Schoolwerth AC, et al. Kidney disease as a risk factor for development of cardiovascular disease: a statement from the American Heart Association Councils on Kidney in Cardiovascular Disease, High Blood Pressure Research, Clinical Cardiology, and Epidemiology and Prevention. Circulation 2003:108:2154-69. 
29 McCullough PA, Steigerwalt S, Tolia K, et al. Cardiovascular disease in chronic kidney disease: data from the Kidney Early Evaluation Program (KEEP). Curr Diab Rep 2011;11:47-55.

30 Yusuf S, Hawken S, Ounpuu S, et al. Effect of potentially modifiable risk factors associated with myocardial infarction in 52 countries (the INTERHEART study): case-control study. Lancet 2004;364:937-52.

31 National Cholesterol Education Program (NCEP) Expert Panel on Detection, Evaluation, and Treatment of High Blood Cholesterol in Adults (Adult Treatment Panel III). Third report of the National Cholesterol Education Program (NCEP) expert panel on detection, evaluation, and treatment of high blood cholesterol in adults (adult treatment panel III) final report. Circulation 2002;106:3143-421.

32 Whelton S, Chow GV, Ashen D, et al. Dyslipidemia management for secondary prevention in women with cardiovascular disease: what can we expect from non-pharmacologic strategies? Curr Cardiovasc Risk Rep 2012;6:443-9.

33 Vetrano DL, Foebel AD, Marengoni A, et al. Chronic diseases and geriatric syndromes: the different weight of comorbidity. Eur J Intern Med 2016;27:62-7.

34 Ahmadi B, Alimohammadian M, Yaseri M, et al. Multimorbidity: epidemiology and risk factors in the Golestan Cohort Study, Iran: a cross-sectional analysis. Medicine 2016;95:e2756.

35 Forman DE, Maurer MS, Boyd C, et al. Multimorbidity in older adults with cardiovascular disease. J Am Coll Cardiol 2018;71:2149-61.

36 Alimohammadian M, Majidi A, Yaseri M, et al. Multimorbidity as an important issue among women: results of a gender difference investigation in a large population-based cross-sectional study in West Asia. BMJ Open 2017;7:e013548.

37 Puth M-T, Weckbecker K, Schmid M, et al. Prevalence of multimorbidity in Germany: impact of age and educational level in a cross-sectional study on 19,294 adults. BMC Public Health $2017 ; 17: 826$
38 Appleton S, Song L. Life satisfaction in urban China: components and determinants. World Dev 2008;36:2325-40.

39 Idler EL, Benyamini Y. Self-rated health and mortality: a review of twenty-seven community studies. J Health Soc Behav 1997;38:21-37.

40 Xue Y, Liu G, Geng Q. Associations of cardiovascular disease and depression with memory related disease: a Chinese national prospective cohort study. J Affect Disord 2020;260:11-17.

41 Toffalini E, Borella E, Cornoldi C, et al. The relevance of memory sensitivity for psychological well-being in aging. Qual Life Res 2016;25:1943-8.

42 Yuan X, Liu T, Wu L, et al. Validity of self-reported diabetes among middle-aged and older Chinese adults: the China Health and Retirement Longitudinal Study. BMJ Open 2015;5:e006633.

43 Yang L, Weng X, Subramanian SV. Associations between older adults' parental bereavement and their health and well-being: evidence from the China Health and Retirement Longitudinal Study. J Affect Disord 2020;272:207-14.

44 Ouyang P, Sun W, Wang C. Well-being loss in informal care for the elderly people: empirical study from China national baseline CHARLS. Asia Pac Psychiatry 2019;11:e12336.

45 Liang Y, Lu P. Effect of occupational mobility and health status on life satisfaction of Chinese residents of different occupations: logistic diagonal mobility models analysis of cross-sectional data on eight Chinese provinces. Int J Equity Health 2014;13:15.

46 Salisbury C. Designing health care for the people who need it: James MacKenzie Lecture 2018. Br J Gen Pract 2019;69:458-9.

47 Azuero A, Williams CP, Pisu M, et al. An examination of the relationship between patient satisfaction with healthcare and quality of life in a geriatric population with cancer in the southeastern United States. J Geriatr Oncol 2019;10:787-91. 